\title{
Interdisciplinary approach in multiple rib fractures
}

\section{Çoklu kosta kırıklarında interdispliner yaklaşım}

\author{
Gökhan GÜNEREN ${ }^{1}$, Oğuz KAYIRAN ${ }^{2}$, Seyit Ali KIZILKAYA ${ }^{3}$
}

\begin{abstract}
Rib fractures are painful injuries that need intensive care which may prolong the patient's stay in hospital. The management consists of either a conservative approach or surgery. A consensus does not exist on methods and materials will be chosen in surgical techniques. Between April and December 2010, 14 multiple rib fractures were treated using interdisciplinary approach with open surgical reduction and plate-screw fixation. The patients stayed at an average of 1.5 days in the intensive care units and 5 days in the hospital. These bed occupancy rates were found to be quite low compared with our general practice. No wound problems were observed. Complete pain control could be established with a single painkiller. We think that interdisciplinary coordination can achieve improvement in surgical success, lower pulmonary complication rates and hospital stay with diminished cost and an increase in patient satisfaction.
\end{abstract}

Key words: Multiple rib fractures, rigid fixation, plate-screw öz

Kosta kırıkları hastanın hastanede kalış süresini uzatan, yoğun bakım ve gögüs tüpü gereksinimi olan ve ağrılı bir travmadır. Tedavisinde konservatif yaklaşılabileceği gibi cerrahi de uygulanmaktadır. Cerrahi teknikler içerisinde hangi metodun ve materyalin kullanılacağına dair bir fikir birliği mevcut değildir. Nisan ve Aralık 2010 tarihleri arasında 14 çoklu kosta kırığı olan hastaya interdisipliner olarak açık cerrahi redüksiyon ve plak-vida ile fiksasyon uygulandı. Ortalama 1,5 gün yoğun bakımda ve 5 gün de hastanede kalış süreleri elde edildi. Bu oranlar genel pratiğimize kıyasla oldukça düşük olarak tespit edildi. Hastalarda yara yeri sorunları izlenmedi. Ağrı kontrolü tek bir ilaçla tam yanıt olarak sağlanabildi. Disiplinler arası koordinasyonun, açık redüksiyon ve internal fiksasyon yapılan çoklu kosta kırıklarında cerrahi başarıyı artırdığını, hastanede kalış süresini ve dolayısı ile maliyetleri azalttığını, pulmoner komplikasyonların önüne geçtiğini ve hasta memnuniyetini artırdığını düşünüyoruz.

Anahtar kelimeler: Çoklu sosta kırıkları, rijid fiksasyon, plak-vida

\section{GíRiş}

Künt toraks travmaları \%35-40 gibi oranda kosta fraktürleri barındırmaktadır ${ }^{1}$. Bu oran azımsanmayacak ölçüde yüksektir. Çoklu kosta kırıklarında çok ciddi solunum sorunları ortaya çıkabilmektedir. Hastalarda yoğun ağrı ile dispne ve yetersiz inspiryum sebebi ile pulmoner komplikasyonlarda ve özellikle atelektazide artma meydana gelebilmektedir. Bu da hastanın hastanede kalma süresinin artmasına, uzun yoğun bakım izlemine ve morbidite artımına, sonuçta yüksek hasta maliyetine yol açmaktadır ${ }^{1}$. Literatüre bakıldığında kosta fiksasyonlarının bu komplikasyonları azaltmak için tercih edildiği ve drenajın uzun sürmesi, hematom mevcudiyeti ve uzamış ağrı durumları gibi endikasyonlarda yapıldığı görülmektedir ${ }^{1}$. Yelken göğüs olgularında da erken entübasyon, agresif ağrı kontrolü ve mekanik ventilasyon ile efektif akciğer havalanması sağlanmaya çalışılmaktadır. Bu durumlarda uzamış yoğun bakım izlemi, uzun hastane kalış süresi ve maliyeti ve bunun sonunda da pulmoner komplikasyonlarda artma, sepsis ve barotravma meydana gelebilmektedir ${ }^{1-5}$.

Göğüs duvarı stabilizasyonu için fiksasyon amaçlı çelik ve titanyum tel, klips ve bar kullanımı, plak-vida sistemleri gibi yöntemler mevcuttur ${ }^{6}$.

Biz, burada hastaların yaşam kalitesini artırmak ve olası pulmoner komplikasyonları azaltmak amacıyla

Received: 19.11.2015

Accepted: 09.12.2015

${ }^{1}$ Muğla Milas Devlet Hastanesi, Göğüs Cerrahisi

${ }^{2}$ Ms Baltalimanı Kemik Hastalıkları Eğitim ve Araştırma Hastanesi, Plastik ve Rekonstrüktif Cerrahi Kliniği

${ }^{3}$ Serbest Hekim, Plastik ve Rekonstrüktif Cerrahi

Yazışma adresi: Oğuz Kayıran, Ms Baltalimanı Kemik Hastalıkları Eğitim ve Araştırma Hastanesi, Plastik ve Rekonstrüktif Cerrahi Kliniği , İstanbul e-mail:droguzk@yahoo.com 
çoklu kosta kırıklarına redüksiyon ve plak-vida sistemleri ile rijid fiksasyon uyguladık. Eksplorasyon için göğüs cerrahisi, redüksiyon ve fiksasyon için plastik Cerrahi ekipleri koordineli olarak çalışarak ameliyatlar gerçekleştirildi.

\section{MATERYAL ve METOD}

Nisan-Aralık 2010 arasında acil servise başvuran toraks travması ve kosta kırıkları olan hastalar değerlendirmeye alındı. Grafilerinde çoklu kırı̆ı̆ olan hastaların tamamı, yandaş diğer sorunlar nedeni ile cerrahi yoğun bakıma alındı. İntratorasik hematom ve eşlik eden ağrısı olanlar, interkostal sinir bloğuna ve analjeziye rağmen, ağrıda hafifleme olmayan ve eşlik eden drenden uzun süre sızıntısı olan hastalar, yelken göğüs deformitesi olan hastalar ameliyata alındı.

Tüm hastalara ameliyat öncesi ön-arka akciğer grafisi (Figür 1) ve parankim hasarı açısından bilgisayarlı tomografi ile inceleme yapıldı. Postoperatif dönemde tüm hastalar kontrol grafileri ile yine değerlendirildi.

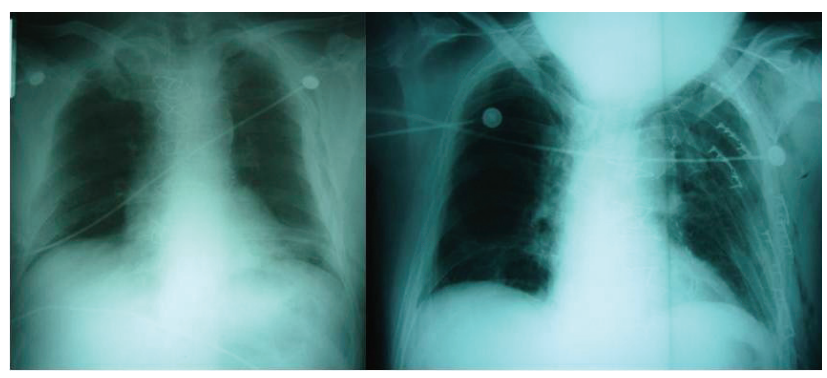

Figür 1. Bir hastaya ait sol hemitoraksta 2.-7. kostalar arası kırıklar solda ameliyat öncesi ve sağda plak-vida ile fiksasyon sonrası görüntüler ön-arka direkt grafide izlenmektedir.

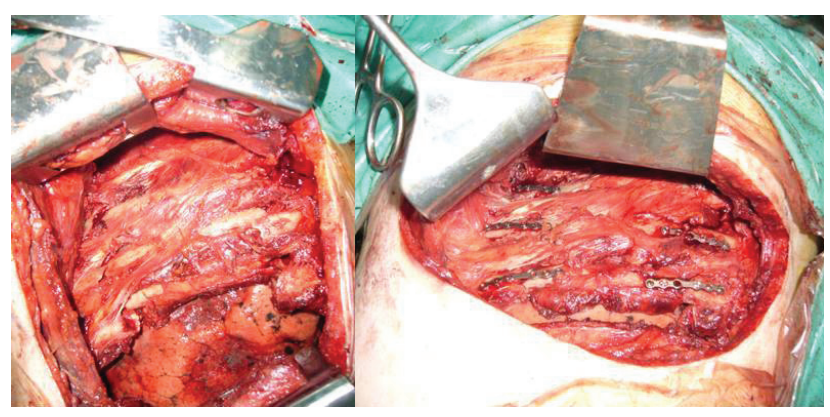

Figür 2. Aynı hastaya ait intraoperatif görüntüler, solda eksplorasyon sırasında ve sağda plak-vida ile fiksasyon sonrası görülmektedir.
Ameliyat sırasında kosta redüksiyon ve fiksasyonu plastik cerrahi ekibi tarafından (Figür 2), cerrahinin geri kalan tüm basamakları ve hasta bakımları göğüs cerrahisi ekibi tarafından gerçekleştirilmiştir.

\section{Ameliyat}

Tüm hastalar genel anestezi altında lateral dekübit pozisyonunda opere edildi. İpsilateral akciğer söndürülerek toraksa girildi ve kostalar arası açılarak parankim kontrolleri yapıldı, varsa hematom boşaltılarak parankim yaralanmaları sütüre edildi. Tüm kırık kostalar, üzerlerindeki periost ve perikondrium diseke edilerek ortaya konuldu. Kırık uçları redükte edilerek uygun anatomik pozisyona getirildi. Osteosentez sırasında kırık uçlarına küretaj yapılıp interpoze olan dokular temizlendi. Fiksasyon yapılırken delgi ile sıvılı ortamda 3500 rpm. de delikler açıldı. Stabilizasyon iki segment arasında her iki yanda en az 3 vida ile olacak şekilde planlandı. Bu şekilde, plakların küçük olduğu için ele gelmemesi ve kullanılan vidalarında kosta altından çıkmayarak komşu parankim yaralanması yapmaması hedeflendi.

Redüksiyon sonrası kortikal miniplak ve kilitsiz minivida ile fiksasyon sağlandı ve toraks tüpü yerleştirildi. Hastalar ekstübe edilerek yoğun bakıma alındı. Tüm hastalar ameliyat sonrası erken dönemde yoğun bakımda drenaj ve kontrol akciğer grafileri ile izlendi.

\section{BULGULAR}

Nisan-Aralık 2010 arasında toraks travması ve kosta kırığı nedeni ile 47 hasta acil servise başvurdu. Bunlardan 14'ünde çoklu kosta kırığı mevcut idi. Hastaların tamamına gögüs tüpü takıldı.

Hastaların etiyolojilerine bakıldığında 6 hastada trafik kazası, 5 hastada yüksekten düşme ve 3 hastada künt travma mevcuttu. On erkek (\%71), 4 kadın (\%29) hasta opere edildi.

Ortalama kırık kosta sayısı 5 (3-7) olarak bulundu. Fiksasyon yapılan toplam kosta sayısı ortalama 4,5 (4-6) olarak bulundu. Ek yandaş sorunu olan hastala- 
rın üçünde klavikula fraktürü, birinde vertebra kompresyon kırığı, ikisinde radius kırığı, birinde tibia kırığı ve sekizinde de pnömotoraks saptandı. Postoperatif yoğun bakımda kalma süresi ortalama 1,42 (1-3) gün, toplam hospitalizasyon süresi ortalama 5,14 (3-7) gün olarak hesaplandı. Hastanede kalış süreleri postoperatif dönemde tüplerin çekildiği aynı gün taburculuk ya da diğer sorunlar için diğer bölümlere devir şeklinde gerçekleşti. Hiçbir hastamızda yara yeri problemi izlenmedi.

\section{TARTIŞMA}

Kosta kırıkları genellikle tedavi edilmeksizin iyileşen ve hastaların semptomatik olarak tedavi edildikleri olgulardır. Ancak, çoklu kosta kırı̆̆ı olan durumlarda tedavi redüksiyona yönelik zorunlu hâle gelebilmektedir. Bu durumlar yeterli medikal tedavilere rağmen, uzamış ağrı, kanama, parankimde hasar, hematom, postür bozukluğu ve yelken göğüs deformitesi gibi durumlarıdır. $\mathrm{Bu}$ bulgularla hastaların pulmoner komplikasyon olasılıkları artmakta ve hastanede kaIış süreleri uzayabilmektedir. Hastane enfeksiyonları açısından da ayrı bir riske girebilmektedirler. Hastaların normal yaşamlarına dönme süreleri uzamakta ve yaşam kalitelerinde de azalma meydana gelebilmektedir $^{1}$.

Kosta kırıkları, aynı zamanda göğüs kafesinde meydana gelen deformite, postür ve şekil bozukluğuna yol açabilmektedir. Bu durumda postoperatif dönemde hastanın beden imajı olumsuz etkilenebilmektedir. Cerrahi olarak göğüs duvarı stabilizasyonun birçok avantajı bildirilmiştir. Bunlar mekanik ventilasyon süresinde azalma, hospitalizasyon süresinde kısalma, yoğun bakım izleminde kalma süresinin azlaması ve sonuçta respiratuvar disfonksiyon oranının ve postür deformitesinin azalmasıdır ${ }^{1-3}$.

Operasyon direkt olarak torakatomi yapmadan ve toraksa girmeden ilgili kırık segment üzerinden de yapılabilir. Yeni yapılan bir çalışmada, video yardımIı torakoskopik cerrahi ile intramedüller titanyum elastik teli kullanılmıştır. Burada, künt kosta travması olan hastalara açık torakostaomi yapılmadan kos- ta fiksasyonları sağlanmıştır ${ }^{6}$. Ancak, olgularımızda mevcut bulgular ve semptomlardan dolayı parankim ve toraks içeriğinin de ekspoze edilmesini gerektirdiğinden, çoklu kırıklar için multiple insizyonlar yapmak yerine tek bir insizyon ile girilerek tüm kırıkları redükte etmeyi ve ilgili intratorasik yaralanmalara müdahale etmeyi amaçladık.

Literatürde plak vida kullanılarak yapılan rijid fiksasyon ile ilgili çok bilgiye rastlanmamaktadır. Üç olguluk iki farklı seride göğüs duvarı fiksasyonunda mandibula rekonstruksiyon plakları kullanılmıştır ${ }^{1,7}$. 2012'de yapılan bir çalışmada ise, klips ve bar kullanımı ile plak-vida kullanımı karşılaştırılmış ve kosta fiksasyon yapmanın yapmamaya göre daha avantajlı olduğu, ancak her iki sistemin birbirine üstünlüğünün bulunmadığı belirtilmiştir ${ }^{8}$. Yeni yapılan bir olgu sunumunda da göğüs duvarı açılmadan 2. ile 8. kostaların plakvida sistemleri ile rijid fiksasyonu paylaşılmıştır ${ }^{9}$. Bu çalışmaların ortak sonucu, hastalarda yoğun bakım ve hastanede kalış sürelerinin kısalması, göğüs duvarı anatomik bütünlüğünün yeniden başarı ile oluşturulması ve göğüs tüpü gereksiniminin azalmasıdır. Biz de benzer olarak ameliyat sonrası hastalarımızın tamamında ağrı ve yoğun bakım gereksiniminde azalma izledik. Böylece, anatomik olarak bütünlüğü sağlanmış olan göğüs kafesinin yapısından dolayı akciğerlerin yeterli ekspansiyonun sağlanmış olması ile ventilatör gereksinimi azaltılmıs oldu. Aynı zamanda kırık stabilizasyonu sonrasında ek bir önlem almaksızın basit analjezik ve antienflamatuvarlar ilaçlar ile ağrının kontrol edilmesi yeterli ekspiryum ve inspiryum için olanak sağladı. Hastaların mobilizasyonları çok erken sağlanabildi. Bu bulgular literatür ile uyum göstermektedir ${ }^{10,11}$.

Kalıcı titanyum plak yerine emilebilir plaklar aynı amaçla kullanılabilir. İyileşme sonrasında plak ve vidaların emileceği düşünüldüğünde çok daha konforlu kabul edilebilir; ancak aynı hasta için 10 kata kadar çıkabilecek olan yüksek maliyet oranı ve grafilerde görülememesi dezavantajları olarak sayılabilir. Titanyum alaşımlı plakların direkt grafilerde görülebilmesi büyük avantajlarından biridir. Postoperatif direkt grafiler ile preop grafiler karşılaştırıldığında anatomik 
bütünlüğün tam olarak sağlandığı izlenmiştir. Hastalarımızın hiçbirinde plak ekspozisyonu ya da çıkarılmayı düşündürecek herhangi bir komplikasyon gelişmemiş olması emilebilir plak kullanımını zorunlu hâle getirmemiştir.

Açık redüksiyon ve fiksasyon ile kosta kırıklarının tedavisi, hastaların yaşam kalitesini arttıran, olası komplikasyonları azaltan, hastanede kalış süresini ve maliyetini azaltan, işe dönme zamanını kısaltan, uygun endikasyonlarda yararlı bir yöntemdir. Bu şekilde hasta konforunda ve yaşam kalitesinde artma sağlanabilecektir. Bu cerrahi sırasında iki ekip olarak disiplinler arası koordineli yaklaşımın uygulanmasının bu sonuçları daha da güvenilir ve cerrahi başarıyı artıracağını düşünmekteyiz.

\section{KAYNAKLAR}

1. Balci AS, Ayan E, Özalp K, et al. Posterolateral Kosta Fraktürlerinde Operatif Fiksasyon: Titanyum Materyal ve Radyolojik Uyumlulugun Degerlendirilmesi. Turkish J Thorac Cardiovasc Surg 2005;13:37-40.

2. Beal $S$, Oreskovitch M. Long term disabililty associatedwith flail chest injury. Am J Surg 1985;150:324-6. http://dx.doi.org/10.1016/0002-9610(85)90071-6
3. Middleton C, Edwards M, Lang N, et al. Management and treatment of patients with fractured ribs. Nurs Times 2003;99:30-2.

4. Lardinois $\mathrm{D}$, Krueger $\mathrm{T}$, Dusmet $\mathrm{M}$, et al. Pulmonary function testing after operative stabilisation of the chest wall for flail chest. Eur J Cardiothorac Surg 2001;20:496-501. http://dx.doi.org/10.1016/S1010-7940(01)00818-1

5. Labitzke R, Schmit-Neuerburg K, Schramm G. Indikation zur Thoracotomie und Rippenstabilisierung beim Thoraxtrauma im hohen Lebensalter. Chirurg 1980;51:576-580.

6. Tarng YW, Liu YY, Huang FD, et al. The surgical stabilization of multiple rib fractures using titanium elastic nail in blunt chest trauma with acuterespiratory failure. Surg Endosc 2015, 15. http://dx.doi.org/10.1007/s00464-015-4207-9

7. Engel C, Krieg JC, Madey SM, et al. Operative Chest Wall Fixation with Osteosynthesis Plates. J Trauma 2005;58:181-186. http://dx.doi.org/10.1097/01.TA.0000063612.25756.60

8. Billè A, Okiror L, Karenovics W, et al. Experience with titanium devices for rib fixation and coverage of chest wall defects. Interact Cardiovasc Thorac Surg 2012;15(4):588-95. http://dx.doi.org/10.1093/icvts/ivs327

9. Maury JM, Roquet G, Marcotte G, et al. Surgical fixation of rib fractures in chest wall trauma. Intensive Care Med 2015;41(8):1483-4. http://dx.doi.org/10.1007/s00134-015-3684-6

10. Mayberry JC, Kroeker AD, Ham LB, et al. Long-term morbidity, pain, and disability after repair of severe chest wall injuries. Am Surg 2009;75(5):389-394.

11. Sarıtaş A, Guneren G, Sarıtaş PU, et al. The Decrease of the Duration of Stay in the ICU with Rib Fixation in a Case of Multiple Rib Fracture. Turk J Anaesth Reanim 2014;42:277-9. http://dx.doi.org/10.5152/TJAR.2014.67044 